\title{
Effects of oxymatrine on the adhesion of human hepatoma cell line QGY-7703 and the expression of integrin $\beta 1$.
}

\author{
Shuguang Zhu ${ }^{1 *}$, Kaiyun Chen ${ }^{2 *}$, Hua Li ${ }^{1}$, Guihua Chen ${ }^{1}$ \\ ${ }^{1}$ Department of Hepatology Surgery, the Third Affiliated Hospital of Sun Yat-sen University, Guangzhou, PR China \\ ${ }^{2}$ Department of General Surgery, Guangdong No.2 Provincial People’s Hospital, Guangzhou, PR China
}

\begin{abstract}
Background: To explore the effect of Oxymatrine (OM) on cell-matrix adhesion of human hepatoma cell line QGY-7703 and the expression of integrin $\beta 1$.

Methods: The effect of OM on cell-matrix adhesion of human hepatoma cell line QGY-7703 was determined with cell adhesion assay and the effect on the mRNA and protein expression of integrin $\beta 1$ in QGY-7703 cells was detected by quantitative PCR and Western blot.

Results: Compared with the control group, QGY-7703 cell-matrix adhesion in the group treated with 1 mg.mL $L^{-1} \mathrm{OM}$ was not inhibited, while the groups treated with $2.5 \mathrm{mg} \cdot \mathrm{mL}^{-1}$ and $5 \mathrm{mg} . \mathrm{mL}^{-1} \mathrm{OM}$ treated cells $(P<0.05)$ was significantly inhibited $(p<0.05)$, accompanied by the decreased mRNA and protein expression of integrin $\beta 1(\mathbf{P}<\mathbf{0 . 0 5})$.

Conclusion: In vitro OM can inhibit the cell-matrix adhesion and mRNA and protein expression of integrin $\beta 1$ of human hepatoma cell line QGY-7703.
\end{abstract}

Keywords: Oxymatrine (OM), Hepatocarcinoma cells, Cell-matrix adhesion, Integrin $\beta 1$.

Accepted on August 03, 2017

\section{Introduction}

Oxymatrine (OM) is the main component of alkaloids in Sophora japonica, Sophora flavescens and Sophora alopecuroides and its molecular formula is $\mathrm{C}_{15} \mathrm{H}_{24} \mathrm{~N}_{2} \mathrm{O}$. Some studies have shown that oxymatrine has anti-virus, anti-liver fibrosis, antiarrhythmic, anti-inflammatory effect [1-4]. Not only that, $\mathrm{OM}$ was also found to have an effect on anti-tumor. For example, OM can inhibit proliferation and migration of human glioblastoma cells by induction of apoptosis [5]. It is now demonstrated that oxymatrine has a significant inhibitory effect on hepatocellular carcinoma cells, which may be achieved by inhibiting cancer cell division and reducing cytotoxicity [6,7]. However, it has also been found that OM, at the dose of $320 \mathrm{mg} / \mathrm{kg}$, has a damaging effect on liver [8]. Integrin $\beta 1$, a member of the $\beta$ sub-family, forms dimers with eight different $\alpha$ subunits in vertebrates [9]. Some researchers suggested that $\beta 1$-null cells from various types of cancer became sensitive to chemotherapy and radiotherapy, because integrin $\beta 1$ regulates viability and proliferation [10-12]. Cellextracellular matrix adhesion is a fundamental process that is important in multiple hallmarks of breast cancer, including conferring a proliferative advantage, inducing pro-survival pathways and driving cell migration and invasion $[13,14]$. Both integrin $\beta 1$ and cell-extracellular matrix adhesion are related to the onset of human cancers $[12,14]$. It has not yet been clearly reported that $\mathrm{OM}$ plays a role in the migration and invasion of liver cancer cells. Therefore, the aim of this study is to investigate the effect of different concentration $\mathrm{OM}$ on the cell adhesion of human hepatocellular carcinoma cell line QGY-7703 and integrin $\beta 1$ expression, and related possible molecular mechanism.

\section{Materials and Methods}

\section{Cells and reagent}

Oxymatrine was purchased from Shaanxi Huike Plant Development Co., Ltd. (China), purity of $98 \%$. Human liver cancer cell line QGY-7703 was donated by Tianjin Life Science Center (China). RPMI1640 cell culture mediums were purchased from Gibco Co., Ltd. (USA). Trizol, RT-PCR kit, SYBR Green ERTM qPCR SuperMix kit was purchased from Dalian Baosheng Biotech Co., Ltd. (China). Matrigel was purchased from Becton, Dickinson and Company (New Jersey, USA). The antibody was purchased from Tianjin Purcell Biotechnology Company (China).

\section{Cell culture}

The human hepatocellular carcinoma cell line QGY-7703 was cultured in RPMI1640 containing $10 \%$ calf serum, 100 IU.mL $\mathrm{mL}^{-1}$ penicillin and streptomycin at $37^{\circ} \mathrm{C}$ in $5 \% \mathrm{CO}_{2}$ incubator. The cells were digested with $0.1 \%$ trypsin $(0.02 \%$ EDTA) and passaged once every 2-3 d. 


\section{Administration and grouping}

Each individual experiment was provided with blank control group, cell control group and experimental group. The cells in the logarithmic growth phase were inoculated into 24-well cell culture plates at $4 \times 10^{5} \mathrm{~mL}^{-1}$. The blank control group only added the cell culture medium $(2 \mathrm{~mL} / \mathrm{well})$ without cells. The cell control group only added cells $(2 \mathrm{~mL} /$ well) without OM. The cells and OM $(2 \mathrm{~mL} /$ well $)$ were added in the experimental group, and divided into $1,2.5$ and $5 \mathrm{mg} \cdot \mathrm{mL}^{-1}$ concentration groups based on the OM concentration (OM 1, OM 2.5, OM 5 group).

\section{Cell adhesion assay for cell-matrix adhesion detection}

The Matrigel gel was coated on each well of a 96-well plate and the extracellular matrix was imitated with Matrigel. The cells were then digested with trypsin for $48 \mathrm{~h}$ to adjust the cell density to $2.5 \times 10 \mathrm{~mL}^{-1}$, and the $100 \mu \mathrm{L}$ cell suspension was added to the 96 -well plate. The plates were incubated for $3 \mathrm{~h}$ at $37^{\circ} \mathrm{C}$, the supernatant was removed, washed twice with $1 \times$ PBS and $100 \mu \mathrm{L}$ bovine serum albumin $(0.5 \%)$ was added to each well at $37^{\circ} \mathrm{C}$ to block for $2 \mathrm{~h}$, again remove the supernatant, wash with $1 \times$ PBS twice. Five wells were set in each group, and placed in $37^{\circ} \mathrm{C}$ incubator for continue culture. The supernatant were removed at 30,60 and $90 \mathrm{~min}$ after culturing, and the cells were washed three times with PBS to wash off cells that did not adhere. Then, $100 \mu \mathrm{L}$ RPMI 1640 complete culture medium and $100 \mu \mathrm{L}$ MTT were added to each well, and placed in $37^{\circ} \mathrm{C}$ incubator to continue culture for $4 \mathrm{~h}$. Then, take the culture plate and, centrifuge at room temperature for $5 \mathrm{~min}$ at the speed of $3000 \mathrm{r} \cdot \mathrm{min}^{-1}$. Afterwards, the supernatant was discarded and $100 \mu \mathrm{L}$ DMSO was added to dissolve the granules. The plates were placed on a shaker and shaken at room temperature for $20 \mathrm{~min}$. The absorbance values (A570 nm) at wavelength of $570 \mathrm{~nm}$ were measured with a microplate spectrophotometer.

\section{Real-time fluorescence quantification}

PCR was used to detect the expression of integrin $\beta 1$ mRNA. The cells in logarithmic growth phase were inoculated into 25 $\mathrm{mL}$ cell culture flasks $\left(2.5 \times 10^{5}\right.$ cells/bottle $)$ and $3 \mathrm{~mL}$ per bottle. After the cells were adhered, OM was added for $48 \mathrm{~h}$ culture and the total RNA of each group was extracted (Trizol method). RT kit was used to synthesize cDNA. Real-time quantitative PCR kit was utilized for PCR reaction. The primer sequence used was as following: integrin $\beta 1$ primer: Upstream 5'-ATG AAT TTA CAA CCA ATT TTT C-3'; Downstream 5'TCA TTT TCC CTC ATA CTT CG-3'; $\beta$-actin primer: Upstream 5'-CCT CAT GCC ATC CTG CGT CTG- 3'; Downstream 5'-TTG CTC GAA GTC TAG GGC AAC ATA G-3'. The reaction system was as following: template cDNA, 1 $\mu \mathrm{L}$; upstream primer $(5 \mu \mathrm{M}), 1 \mu \mathrm{L}$; downstream primer $(5 \mu \mathrm{M})$, $1 \mu \mathrm{L} ; 2 \times$ SYBR GreenERTM qPCR SuperMix, $10 \mu \mathrm{L}$; sterilized double distilled water, $7 \mu \mathrm{L}$; total volume $20 \mu \mathrm{L}$. PCR reaction conditions: (1) $95^{\circ} \mathrm{C} 3 \mathrm{~min}$ (pre-denaturation); (2) $94^{\circ} \mathrm{C} 30 \mathrm{~s}$ (denaturation); (3) $57^{\circ} \mathrm{C} 30 \mathrm{~s}$ (annealing); (4) $72^{\circ} \mathrm{C} 30 \mathrm{~s}$ (extended, extended terminal SYBR fluorescence signal acquisition); 40 cycles for steps (2)-(4). The relative content of integrin $\beta 1$ in the sample was calculated (compared with the reference gene $\beta$-actin), calculated as: $2^{-\Delta \Delta C t}$, where $\mathrm{Ct}=(\mathrm{ct}$ (integrin $\beta 1$ in experimental group)- $\mathrm{Ct}$ ( $\beta$-actin in experimental group)-(Ct (integrin $\beta 1$ in control group)-Ct $(\beta$ actin in control group)).

\section{Western blot for integrin $\beta 1$ expression}

The cells in logarithmic growth phase were seeded in 24-well plate $\left(2 \times 10^{4} /\right.$ well $), 1 \mathrm{~mL}$ per well. After cell adherence, OM was added and the cells were incubated for 48 hours. Then RIPA lysis buffer was added to prepare cell protein samples. $6 \%$ SDS-PAGE was used for electrophoresis, which was then electro transferred to the nitrocellulose membrane, and placed in blotto buffer at room temperature for $2 \mathrm{~h}$. After that, the membrane placed in the corresponding antibody (anti-integrin $\beta 1$ antibody or rabbit anti-actin antibody, $1: 100$ or $1: 500$ dilution) blotto, shaken overnight at $4{ }^{\circ} \mathrm{C}$, washed with TBST for 3 times ( $5 \mathrm{~min} /$ time). The membrane was placed in blotto containing the corresponding secondary antibody (HRPlabelled goat anti-mouse or goat anti-rabbit $\operatorname{IgG}$ antibody), shaken at room temperature for $1.5 \mathrm{~h}$ at room temperature, washed with TBST for 5 times ( $5 \mathrm{~min} / \mathrm{time}$ ). ECL was used for luminescence and the relative density of integrin $\beta 1$ was analyzed by using image analysis and processing system software for exposure, development and image acquisition. The optical density of each protein band was scanned. In order to calculate the ratio of the optical density of the integrin $\beta 1$ band to the optical density of the corresponding GAPDH (internal reference) band, the corrected integrin $\beta 1$ expression intensity value was calculated. The expression of integrin $\beta 1$ in the experimental groups was compared. The expression of the control group was considered as 1 , the expression of integrin $\beta 1$ in the experimental groups was calculated and the histogram was obtained.

\section{Statistical method}

Data were statistically analyzed with SPSS 16.0. The data were expressed as mean \pm standard deviation $(\overline{\mathrm{x}} \pm \mathrm{s})$. The single factor analysis of variance was applied in multiple samples comparison. $\mathrm{P} \leq 0.05$ means statistically significant differences between the two samples.

\section{Results}

\section{Effect of OM on matrix adhesion of QGY-7703 cell}

The OD (A570 nm) of the three does OM groups and the control group were not the same. Compared with the control group, the OD values of OM 2.5 and OM 5 group were significantly decreased $(\mathrm{P}<0.01)$. Compared with $\mathrm{OM} 1$ group, the OD value of OM 5 group was significantly decreased (P $<0.01$ ) (Figure 1). 


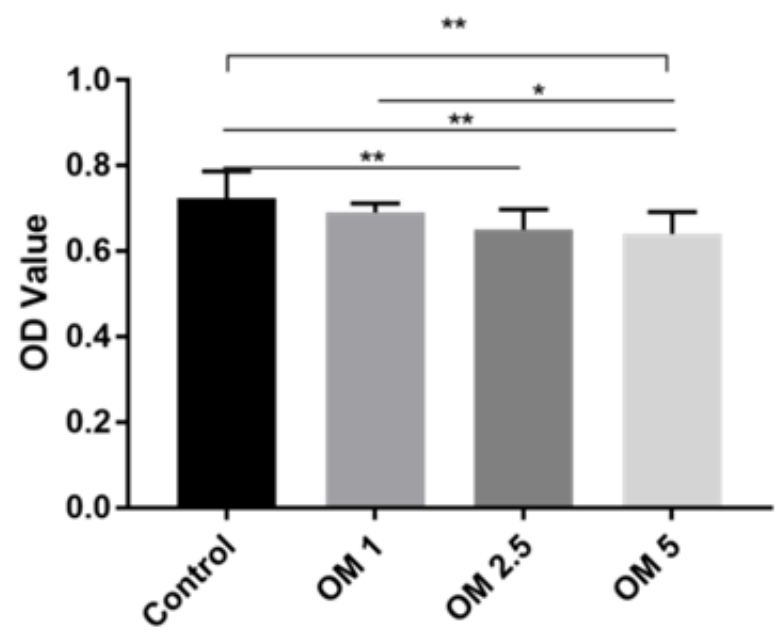

Figure 1. Effect of OM on matrix-adhesion of QGY-7703 cells.

\section{Effect of OM on expression of integrin $\beta 1 \mathrm{mRNA}$ in QGY-7703 cells}

The integrin $\beta 1$ mRNA expression in the OM groups of three doses and the control group of were not the same. Compared with the control group, the levels of $\beta 1$ mRNA in OM 2.5 and OM 5 groups were significantly decreased $(\mathrm{P}<0.01)$. Compared with OM 1 group, $\beta 1$ mRNA levels in OM 2.5 and OM 5 groups were significantly lower $(\mathrm{P}<0.01)$ (Figure 2$)$.

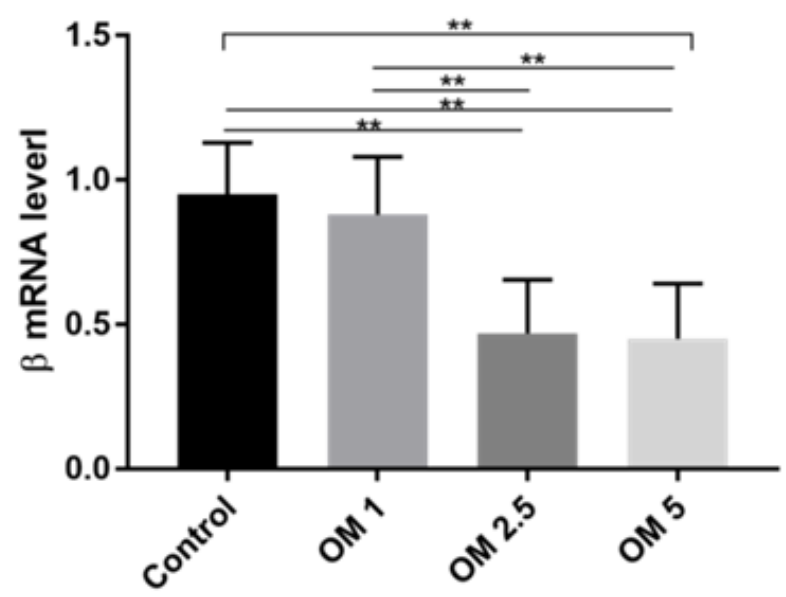

Figure 2. Effect of OM on integrin $\beta 1$ in QGY-7703 cells.

\section{Effect of OM on expression of integrin $\beta 1$ protein in QGY-7703 cells}

The contents of integrin $\beta 1$ protein in OM groups of three does and control group were not the same. Compared with the control group, the levels of $\beta 1$ protein in OM 2.5 and OM 5 groups were significantly decreased $(\mathrm{P}<0.01)$. Compared with OM 1 group, the levels of $\beta 1$ protein in OM 2.5 and OM 5 groups were significantly decreased $(\mathrm{P}<0.01)$. Electrophoresis bands showed that the bands of OM 1, OM 2.5 and OM 5 were also more and more thin with the increased concentrations (Figure 3).

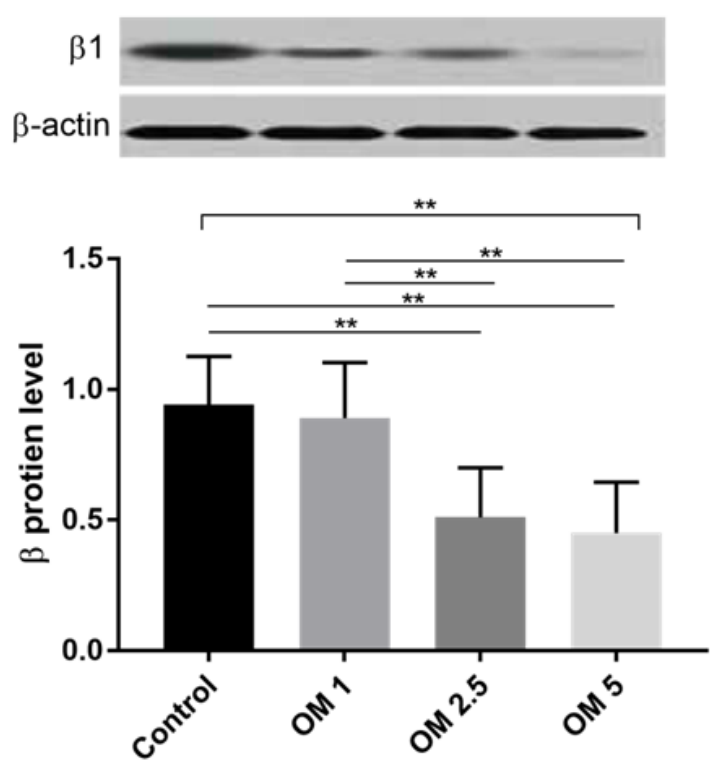

Figure 3. Effect of $O M$ on integrin $\beta 1$ protein expression in QGY-7703 cells.

\section{Discussion}

Hepatocellular carcinoma is the fifth most common type of cancer in the world and is the third leading cause of cancerrelated mortality worldwide [15]. The high mortality of liver cancer is mainly due to high recurrence and metastasis. Liver cancer metastasis is an extremely complex "multi-step" process, liver cancer cells leave the primary tumor and invaded into blood vessels and lymphatic vessels through the extracellular matrix (extracellular matrix, ECM), then the metastases was formed [16]. In this process, the combination of hepatoma cells and ECM is the initial step of invasive growth and distant metastasis of hepatocarcinoma cells [17]. A recent study showed that OM inhibits hepatocyte apoptosis by suppressing the TLR4/PI3K/Akt/GSK-3 $\beta$ signalling pathway [18]. OM has a variety of pharmacological actions. It has a protective effect on ischemic and reperfusion injury in liver, and the intestines and heart via its anti-apoptotic and antiinflammatory activity [19-21]. As a result, this study first used the cell adhesion test to detect the effect of OM on matrix adhesion ability of liver cancer cells. The results showed that $\mathrm{OM}$ at higher concentrations $\left(2.5\right.$ and $\left.5 \mathrm{mg} . \mathrm{mL}^{-1}\right)$ could inhibit the adhesion of hepatocarcinoma cells to matrix. Cell adhesion molecules are one of the important factors of tumor metastasis, tumor metastasis in the various steps involved in the number of cell adhesion molecules or functional changes. Cell adhesion molecules (CAMs) are a class of transmembrane glycoproteins present on the cell surface or ECM that mediate cell-cell or cell-ECM contact with each other by binding to the corresponding ligand on the cell or ECM surface combination. The results suggested that $\mathrm{OM}$ at higher concentrations $(2.5$ and $5 \mathrm{mg} \cdot \mathrm{mL}^{-1}$ ) can inhibit the expression of integrin $\beta 1$ mRNA and protein. The integrin family is a large group of cell adhesion molecules, widely expressed in a variety of tissue cells, which is a heterologous dimer composing of the $\alpha$ and $\beta$ 
subunits of transmembrane protein through non-covalent bond and plays an important role in mediating cell ECM adhesion. Some studies have shown that in tumor cells, expression and function of integrin often have significant changes that have promoting effect on the adherence, migration and invasion and angiogenesis of tumor cells. In hepatocarcinoma cells, the expression of integrin $\beta 1$ was significantly enhanced, playing a key role in the invasion and metastasis. Therefore, after confirmation the inhibitory effect of OM on matrix adhesion in QGY-7703 cells, the integrin $\beta 1$ expression after OM treatment was determined.

\section{Conclusion}

The results demonstrated that the mRNA and protein expression of integrin $\beta 1$ in QGY-7703 cells in OM treatment groups were significantly lower than that in the control group $(\mathrm{P}<0.05)$. However, whether there is a direct causal relationship between the two still need to be further verified in subsequent studies.

\section{References}

1. Wang YP, Liu F, He HW, Han YX, Peng ZG, Li BW, You XF, Song DQ, Li ZR, Yu LY. Heat stress cognate 70 host protein as a potential drug target against drug resistance in hepatitis B virus. Antimicrob Agents Ch 2010; 54: 2070.

2. Ning L, Chai, Qiang, Fu, Hui, Shi, Chang H, Jun, Wan. Oxymatrine liposome attenuates hepatic fibrosis via targeting hepatic stellate cells. World J Gastroenterol 2012; 18: 4199.

3. Guzman JR, Koo JS, Goldsmith JR, Hlbauer MM, Narula A, Jobin C. Oxymatrine prevents NF- $\mathrm{B}$ nuclear translocation and ameliorates acute intestinal inflammation. Sci Rep 2013; 3: 1629.

4. Cao YG, Jing S, Li L, Gao JQ, Shen ZY, Liu Y, Xing Y, Wu ML, Wang Y, Xu CQ. Anti-arrhythmic effects and ionic mechanisms of oxymatrine from Sophora flavescens. Phytother Res 2010; 24: 1844.

5. Liu F, Wang B, Wang J, Ling X, Li Q, Meng W, Ma J. Oxymatrine inhibits proliferation and migration while inducing apoptosis in human glioblastoma cells. BioMed Res Int 2016; 2016: 1.

6. Liu Y, Bi T, Dai W, Wang G, Qian L, Gao Q, Shen G. Oxymatrine synergistically enhances the inhibitory effect of 5-fluorouracil on hepatocellular carcinoma in vitro and in vivo. Tumor Biol 2016; 37: 7589.

7. Ho JW, Ngan Hon PL, Chim WO. Effects of oxymatrine from $\mathrm{Ku}$ Shen on cancer cells. Anticancer Agents Med Chem 2009; 9: 823.

8. Lu H, Zhang L, Gu LL, Hou BY, Du GH. Oxymatrine induces liver injury through JNK signalling pathway mediated by TNF- $\alpha$ in vivo. Basic Clin Pharmacol 2016; 119: 405.

9. Hynes RO. Integrins: bidirectional, allosteric signalling machines. Cell 2002; 110: 673.
10. Han S, Li Z, Master LM, Master ZW, Wu A. Exogenous IGFBP-2 promotes proliferation, invasion, and chemoresistance to temozolomide in glioma cells via the integrin beta1-ERK pathway. Br J Cancer 2014; 111: 1400.

11. Wu J, Li Y, Dang YZ, Gao HX, Jiang JL, Chen ZN. $\mathrm{HAb} 18 \mathrm{G} / \mathrm{CD} 147$ promotes radio resistance in hepatocellular carcinoma cells: a potential role for integrin beta1 signalling. Mol Cancer Ther 2015; 14: 553.

12. Eke I, Zscheppang K, Dickreuter E, Hickmann L, Mazzeo E, Unger K, Krause M, Cordes N. Simultaneous beta1 integrin-EGFR targeting and radiosensitization of human head and neck cancer. J Natl Cancer Inst 2015; 107.

13. Polyak K, Kalluri R. The role of the microenvironment in mammary gland development and cancer. Cold Spring Harb Perspect Biol 2010; 2: a003244.

14. Pickup MW, Mouw JK, Weaver VM. The extracellular matrix modulates the hallmarks of cancer. Embo Rep 2014; 15: 1243 .

15. Bruix J, Sherman M. Management of hepatocellular carcinoma: An update. Hepatol 2011; 54: 1113.

16. Egeblad M, Werb Z. New functions for the matrix metalloproteinases in cancer progression. Nat Rev Cancer 2002; 2: 161.

17. Kudo D, Suto A, Hakamada K. The development of a novel therapeutic strategy to target Hyaluronan in the extracellular matrix of pancreatic ductal adenocarcinoma. Int J Mol Sci 2017; 18: 600.

18. Xian Z, Wei J, Ai-Ling Z. Inhibitory effect of oxymatrine on hepatocyte apoptosisviaTLR4/PI3K/Akt/GSK-3 $\beta$ signaling pathway. World J Gastroenterol 2017; 23: 3839.

19. Hong-Li S, Lei L, Lei S, Dan Z, De-Li D, Guo-Fen Q, Yan L, Wen-Feng C, Bao-Feng Y. Cardio protective effects and underlying mechanisms of oxymatrine against Ischemic myocardial injuries of rats. Phytother Res 2008; 22: 985.

20. Zhao J, Yu S, Tong L, Zhang F, Jiang X, Pan S, Jiang H, Sun $\mathrm{X}$. Oxymatrine attenuates intestinal ischemia/ reperfusion injury in rats. Surg Today 2008; 38: 931.

21. Xiang X, Wang G, Cai X, Li Y. Effect of oxymatrine on murine fulminant hepatitis and hepatocyte apoptosis. Chin Med J 2002; 115: 593.

\section{*Correspondence to}

Shuguang Zhu

Department of Hepatology Surgery

The Third Affiliated Hospital of Sun Yat-sen University

PR China

Kaiyun Chen

Department of General Surgery Guangdong

No.2 Provincial People's Hospital

PR China 